\title{
A cross-sectional investigation of regional patterns of diet and cardio-metabolic risk in India
}

\author{
Carrie R Daniel ${ }^{1 *}$, Dorairaj Prabhakaran², Kavita Kapur ${ }^{3}$, Barry I Graubard ${ }^{1}$, Niveditha Devasenapathy², \\ Lakshmy Ramakrishnan ${ }^{4}$, Preethi S George ${ }^{5}$, Hemali Shetty ${ }^{6}$, Leah M Ferrucci ${ }^{1}$, Susan Yurgalevitch7, \\ Nilanjan Chatterjee ${ }^{1}$, KS Reddy $^{4}$, Tanuja Rastogi ${ }^{8}$, Prakash C Gupta ${ }^{6}$, Aleyamma Mathew ${ }^{5}$, Rashmi Sinha ${ }^{1}$
}

\begin{abstract}
Background: The role of diet in India's rapidly progressing chronic disease epidemic is unclear; moreover, diet may vary considerably across North-South regions.

Methods: The India Health Study was a multicenter study of men and women aged 35-69, who provided diet, lifestyle, and medical histories, as well as blood pressure, fasting blood, urine, and anthropometric measurements. In each region (Delhi, $n=824$; Mumbai, $n=743$; Trivandrum, $n=2,247$ ), we identified two dietary patterns with factor analysis. In multiple logistic regression models adjusted for age, gender, education, income, marital status, religion, physical activity, tobacco, alcohol, and total energy intake, we investigated associations between regional dietary patterns and abdominal adiposity, hypertension, diabetes, and dyslipidemia.
\end{abstract}

Results: Across the regions, more than $80 \%$ of the participants met the criteria for abdominal adiposity and 10 to $28 \%$ of participants were considered diabetic. In Delhi, the "fruit and dairy" dietary pattern was positively associated with abdominal adiposity [highest versus lowest tertile, multivariate-adjusted OR and 95\% Cl: 2.32 (1.03-5.23); $\left.P_{\text {trend }}=0.008\right]$ and hypertension [2.20 (1.47-3.31); $\left.P_{\text {trend }}<0.0001\right]$. In Trivandrum, the "pulses and rice" pattern was inversely related to diabetes [0.70 (0.51-0.95); $\left.P_{\text {trend }}=0.03\right]$ and the "snacks and sweets" pattern was positively associated with abdominal adiposity [2.05 (1.34-3.14); $\left.P_{\text {trend }}=0.03\right]$. In Mumbai, the "fruit and vegetable" pattern was inversely associated with hypertension [0.63 (0.40-0.99); $\left.P_{\text {trend }}=0.05\right]$ and the "snack and meat" pattern appeared to be positively associated with abdominal adiposity.

Conclusions: Cardio-metabolic risk factors were highly prevalent in this population. Across all regions, we found little evidence of a Westernized diet; however, dietary patterns characterized by animal products, fried snacks, or sweets appeared to be positively associated with abdominal adiposity. Conversely, more traditional diets in the Southern regions were inversely related to diabetes and hypertension. Continued investigation of diet, as well as other environmental and biological factors, will be needed to better understand the risk profile in this population and potential means of prevention.

\section{Background}

The Indian population has the highest prevalence of diabetes worldwide [1] and exhibits high-risk metabolic profiles at younger ages and lower body mass index (BMI) than their Western counterparts [2,3]. Although genetic susceptibility is likely to play a role in chronic disease etiology, the strong evidence for diet and other

\footnotetext{
* Correspondence: danielc3@mail.nih.gov

'Division of Cancer Epidemiology and Genetics, National Cancer Institute, (6120 Executive Blvd), Rockville, MD, (20852), USA Full list of author information is available at the end of the article
}

environmental factors [4-7] suggest that such an epidemic may be preventable.

Diets across India have not been widely investigated, yet many believe that India may be in the midst of a "nutrition transition," [8-10] where changes in diet parallel an expanding industrial economy and a rapidly progressing epidemic of obesity and chronic, noncommunicable disease. In this emerging at-risk population, the suspected access to and adoption of a less healthy diet and lifestyle, and/or deviance from traditional and potentially protective behaviors $[9,11,12]$, may
Ciomed Central 
be linked to anthropometric factors and biological markers of chronic disease risk [3,13]. However, few have closely examined the role of diet in these patterns and relationships across a large, diverse, Indian population.

Large cohort studies in the U.S. and Europe have used dietary patterns analyses to bring to light common eating behaviors and their relationships with risk of cardiovascular disease and cancer [14,15]; however, no such studies exist in India. Furthermore, diet is expected to vary considerably within India across North-South regions $[10,13,16]$ and with the exception of national food surveys [9,17], few comprehensive and up-to-date assessments of regional Indian diets are currently available [11,12,18].

Utilizing detailed diet histories collected in a cohort feasibility study conducted across three diverse regions of India, our objective was to aggregate foods in to regional dietary patterns and to investigate associations with cardio-metabolic risk factors, such as abdominal adiposity, hypertension, diabetes, and dyslipidemia. As little is known regarding regional differences, we used an exploratory approach, factor analysis, to empirically identify dietary patterns reflecting actual eating behaviors within each of the study regions $[19,20]$.

\section{Methods}

\section{Study Participants}

The India Health Study (IHS; Figure 1) was a multicenter pilot study designed to investigate the feasibility of establishing a diet and cancer cohort in India. The study was conducted between December 2006 and July 2008 in participating centers distributed across three regions of India: Delhi in the north (All India Institute of Medical Sciences and Centre for Chronic Disease Control), Mumbai in the west (Healis-Sekhsaria Institute for Public Health), and Trivandrum in the south (Regional Cancer Center). Centers were selected in areas with established cancer registries [21] and to capture a range of different economic, ethnic, and urbanization patterns [11]. Human ethics committees from each study center, the Special Studies Institutional Review Board of the U.S. National Cancer Institute, as well as the Indian Health Ministry Screening Committee (part of the Indian Council of Medical Research reporting to the Government of India) reviewed and approved the study.

Households within the centers' coverage areas were identified using census data in Delhi, the voter's registration list in Trivandrum, and an existing cohort [22] database of participants and their neighbours in Mumbai. The IHS households were selected at random from census enumeration blocks in 2 wards in the Hauz Khas subdivision of the South District in Delhi; polling stations in 6 urban and 49 rural wards from the Ned umangadu and Thiruvanthapuram taluks (subdivisions) in Trivandrum; and from 3 representative areas (Parel, Naigaum, Sewri) of Ward F-South in Mumbai [22]. In the largest study region, Trivandrum, households were sampled by religion (Hindu/Muslim/Christian) and urban-rural residence strata to maximize the variability in diet and lifestyle across the IHS. Household eligibility

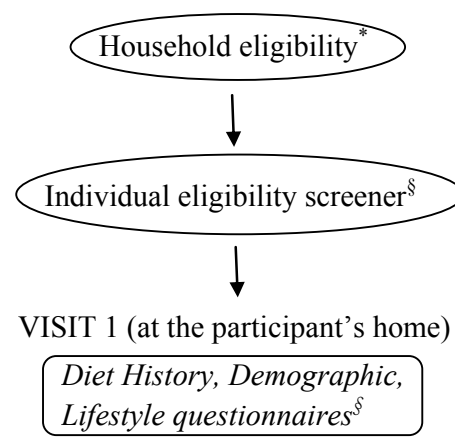

VISIT 2 (at the participant's home or mobile camp)

Medical History
Anthropometry measured
Blood pressure $(B P)$ taken
Fasting blood taken
First morning void collected $^{\dagger}$

Figure 1 India Health Study (IHS): Design, visit flow, and participation rates. *Participant's household selection was stratified by religion, as well as urban-rural status in Trivandrum only. Both Delhi and Mumbai centers are considered to be entirely urban. Religious groups are not evenly distributed throughout the country; therefore, higher concentrations of Muslim and Christian households were recruited from Trivandrum. ${ }^{\S}$ All questionnaires were administered by trained field staff via interview. ${ }^{\dagger}$ In Mumbai, no biological samples were collected and all information was collected in the first visit. ${ }^{*}$ Denominator for completion rates.

\begin{tabular}{|lccccccc|}
\hline $\begin{array}{c}\text { Recruitment and participation: } \\
\text { Individuals within households }\end{array}$ & \multicolumn{1}{c}{ Delhi } & \multicolumn{2}{c|}{ Trivandrum } & \multicolumn{2}{c|}{ Mumbai } \\
Eligible to participate & 1,184 & 3,380 & $(96 \%)$ & 2,702 & $(80 \%)$ & 826 & $(46 \%)$ \\
Signed informed consent & 7 & 942 & $(82 \%)$ & 2,431 & $(90 \%)$ & 804 & $(97 \%)$ \\
Completion $^{*}:$ & & & & & & \\
Questionnaires & 864 & $(92 \%)$ & 2,431 & $(100 \%)$ & 804 & $(100 \%)$ \\
Anthropometric exam and BP & 740 & $(79 \%)$ & 1,728 & $(71 \%)$ & 804 & $(100 \%)$ \\
Fasting blood and urine & 739 & $(78 \%)$ & 1,847 & $(76 \%)$ & - & - \\
\hline
\end{tabular}


was verified by field interviewers during the first inhome recruitment visit.

Individuals within households were eligible to participate if they met the following criteria: 35 to 69 years of age; resided in the study area for a minimum period of 1 year; no prior history of cancer, recent cardiac event, or blood disorders; proficient in English or regional language; capable of informed consent; willing to provide biological samples (feasibility component of pilot cohort); and no physical ailments or limitations preventing them from participating in the study. Eligible female participants could not be pregnant. To achieve a diverse population with variation in diet and other risk factors, one male and one female adult per household were recruited to obtain an approximately equal number of subjects by gender and five-year age category.

From 7,064 households initially identified (Delhi 1,298; Trivandrum 4,915; Mumbai 851), 3,033 (43\%) were successfully contacted. Region-specific rates varied due to different methods of identification and recruitment: Delhi 626 (48\%); Trivandrum 1,720 (34\%); and Mumbai 687 (81\%). From these households, 6,355 individuals aged 35-69 were identified and 4,177 were found to be eligible and willing to participate (Figure 1). In the present analyses, participants (Figure 1) were excluded from entering the factor analysis if they reported less than 15 total food items in the Diet History $(n=27$, 142, 37 in Delhi, Trivandrum, and Mumbai, respectively) or had missing or invalid responses to the medical history questionnaire $(\mathrm{n}=13,42,24)$. Thus dietary pattern values were available for $824,2,247$, and 743 participants. For the purposes of the abdominal adiposity analysis (described in detail below), an additional 121, 458, and 20, were excluded due to missing or implausible height, weight, waist or hip circumference measurements. Across the regions, blood pressure measurements were available for 705 (Delhi), 1,843 (Trivandrum), and 737 (Mumbai) participants to validate medical history data for hypertension (described in detail below). In Delhi and Trivandrum, respectively, 701 and 1,779 participants had valid fasting plasma glucose levels, while an additional 6 and 115 participants had urine sugar values only. Thus, for 707 and 1,894 participants in these two regions we used biological markers to validate diabetes status (described in detail below). In the Mumbai study center, the infrastructure necessary for immediate storage and processing of biospecimens was inadequate and prohibitive; thus, no blood or urine was collected from Mumbai participants.

\section{Data Collection}

Questionnaires and diet assessments were administered via interview by trained field staff in the participants' homes. Socio-demographic, household, diet, physical activity and other lifestyle information, including tobacco and alcohol use, were collected upon enrollment. Anthropometric measures, medical histories, current medications, and biological samples were collected at subsequent visits by medical staff in the participant's home or mobile clinics set up within neighborhoods (Figure 1). In Delhi and Trivandrum, fasting blood, toenail clippings, and first morning void urine specimen were collected at Visit 2. No biological samples were collected in Mumbai due to the lack of proper storage and laboratory resources in the study region.

\section{Assessment of Diet}

Diet was assessed using a computer-based, intervieweradministered, meal-based, comprehensive diet assessment known as the New Interactive Nutrition Assistant- Diet in India Study of $\underline{\text { Health }}$ (NINA-DISH). This software was developed specifically for the IHS by adapting and modifying software originally developed by Novo Nordisk Pharma India (Bangalore, India). The Diet History (DH) component included three sections: a set of defined questions similar to a food-frequency questionnaire (FFQ); an open-ended section for each mealtime to collect additional and unique regional foods; and a food-preparer's questionnaire. To help participants estimate portion sizes, interviewers provided standard food models along with typical serving plates, bowls, and utensils. The NINA-DISH database included a selection of 910 food items over eight meal times (bed tea, breakfast, mid-morning snack, lunch, afternoon tea, evening snack, dinner and bed-time snack). Participants completed the DH within 20 minutes to 1 hour; and across the three regions reported a total of 576 unique food items (212, 316, and 339 foods in Delhi, Trivandrum, and Mumbai, respectively).

There was no single up-to-date and comprehensive Indian food and nutrient database currently available for estimating nutrient values from regional Indian foods [11]; thus, we pooled the relevant data from existing international databases containing Indian foods and recipes. Nutrient values and recipe codes were drawn from the U.K.'s Nutrient Databank/ McCance and Widdowson's The Composition of Foods integrated dataset (CoF IDS), the U.S. Department of Agriculture (USDA)'s Food and Nutrient Database for Dietary Studies (FNDDS), the Singapore Health Promotion Board (HPB)'s Food Info, the Malaysian Foods Composition Database (NutriWeb), the Australian Food Composition Tables (NUTTAB), and the Food and Agriculture Organization of the United Nations (FAO)'s World Food Dietary Assessment System (WorldFood). For items that could not be matched, recipes were developed using a combination of database-matched cooked foods. For each nutrient, we used a standardized unit of measurement and reported 
values per 100 grams of edible portion of food product $[23,24]$.

\section{Blood Pressure, Anthropometry, and Physical Activity}

At the time of the anthropometry exam, systolic and diastolic blood pressure levels were taken by a study nurse using a portable calibrated digital monitor for the upper arm. Using a portable calibrated digital scale (Breuer), stadiometer (Seca 214), and no-stretch measuring tape (Gulick), weight, height, waist circumference, hip circumference, and thigh circumference were taken in duplicate (or triplicate if the first two were not within agreement) and then averaged. Body mass index (BMI) was calculated as weight $(\mathrm{kg}) /$ height $(\mathrm{m})^{2}$ and categories were based on World Health Organization cut-points with special consideration of Asian populations [25]. Abdominal adiposity was estimated with the waist circumference to hip circumference ratio (WHR) [26].

All study participants completed the validated shortform of the International Physical Activity Questionnaire [IPAQ; $[27,28]]$. We estimated total physical activity as the weighted sum of walking, moderate, and vigorous activity in metabolic equivalents of task (MET)-hours per week from recreation, occupation, household work, and transportation-related activity [29].

\section{Biospecimen collection and processing}

In Delhi and Trivandrum, a first morning urine sample $(100 \mathrm{~mL})$ and fasting blood sample $(15 \mathrm{~mL})$ were collected and immediately transported (within three hours) to the respective center's clinical laboratories in coolers for routine processing and analysis using a Beckman Autoanalyzer (Beckman, Fullerton, CA). Fasting glucose levels were determined with the glucose oxidase/peroxidase method [30] (Delhi: GOD-PAP; Randox Laboratories Ltd., Antrim, UK; Trivandrum: GOD-POD; Autospan; Span Diagnostics Ltd., Surat, India). In Delhi, lipid profiles were also analyzed using the following methods: (TC) by cholesterol oxidase/paminophenazone (CHOD-PAP; Randox Laboratories Ltd., Antrim, UK) method, triglyceride by glycerolphosphatase oxidase-peroxidase aminophenazone (GPOPAP; Randox Laboratories Ltd., Antrim, UK) method and HDL cholesterol by precipitation method using phosphotungstate/magnesium-precipitation of apolipoprotein $\mathrm{B}$ containing lipoproteins followed by estimation of cholesterol in supernatant by enzymatic method. LDL cholesterol was estimated using the Friedwald formula [31].

\section{Prevalent abdominal adiposity, diabetes, hypertension, and} dyslipidemia

For the purposes of this analysis, sex-specific cut-points for South Asian [25,26] populations were used to define abdominal adiposity by a WHR greater than or equal to 0.90 in males or 0.80 in females.
Diabetes status was defined by a combination of selfreported medical history, medication use, and fasting plasma glucose levels. Any participants who reported a positive medical history with valid medication use/treatment for high blood sugar were considered diabetes cases; and thus, represented $47 \%$ of the total diabetes cases in Delhi and Trivandrum, and $89 \%$ of the total cases in Mumbai. Note that in Mumbai, no biospecimens were collected and only self-reported medical history was available to define diabetes status. Of the Delhi and Trivandrum participants who did not report a treatment and/or positive medical history for diabetes, case-status was defined by a fasting plasma glucose level greater than or equal to $126 \mathrm{mg} / \mathrm{dl}$ [32]. Fifty-two percent of the total diabetes cases in Delhi and $48 \%$ of the cases in Trivandrum were captured by high fasting blood levels; and thus, represented participants who were likely unaware of their diabetic status. Abovenormal urine sugar ( $>15 \mathrm{mg} / \mathrm{dl}$ or $>0 \%$ ) was also used to define diabetes status in $1 \%$ of the total cases in Delhi and $4 \%$ of the total cases in Trivandrum when fasting blood was unavailable. Among non-cases in Delhi and Trivandrum, $91 \%$ and $94 \%$ were confirmed "normal" by blood levels $(<126 \mathrm{mg} / \mathrm{dl})$ or urine, while the remaining $9 \%$ and $6 \%$ were included as a non-case based on a selfreported negative medical history only. In Delhi and Trivandrum, a variable was similarly created to compare participants with and without pre-diabetes or impaired fasting glucose $(\geq 100 \mathrm{mg} / \mathrm{dl}$ versus $<100 \mathrm{mg} / \mathrm{dl}[32,33])$.

Hypertensive status was similarly defined in all regions by medical history, medication use, and blood pressure levels. A participant was considered hypertensive if they indicated a positive medical history with valid treatment for high blood pressure; otherwise, hypertension was classified based on blood pressure levels measured in the study ( $\mathrm{SBP} \geq 140 \mathrm{mmHg}$ or $\mathrm{DBP} \geq 90 \mathrm{mmHg}$ ). Less than $2 \%$ of hypertension cases were based on a positive self-report only. In Delhi, Trivandrum, and Mumbai, respectively, $13 \%, 8 \%$, and $2 \%$ of non-cases were based only on a negative self-reported history.

Blood cholesterol levels were analyzed for Delhi participants only and dyslipidemia was defined by one or more of the following: HDL cholesterol levels less than $40 \mathrm{mg} / \mathrm{dl}$ in males or $50 \mathrm{mg} / \mathrm{dl}$ in females, TG levels above $200 \mathrm{mg} / \mathrm{dl}$, total cholesterol to HDL ratio greater than or equal to 5 [34].

\section{Statistical Analysis}

We derived dietary patterns for each region separately using factor or principal component analysis (PCA) [20]. Prior to analysis, individual food items collected in the structured $\mathrm{DH}$ and in the open-ended section were aggregated in to 130 common "reference groups" by a trained nutritionist familiar with regional food items, recipes, and 
nutrient content (Table 1). These groups were similar to the level of detail found in a comprehensive FFQ. For example, vegetable items were classified according to their color or botanical group (e.g., red, orange, cruciferous, allium). Next, the reference group data was prepared to enter the factor analysis in a standard manner described elsewhere [19,35]. Very low consumption food groups were either dropped or combined (e.g., Western fast foods) for a total of 104 unique items across all regions. Additional items were dropped in region-specific analyses, as necessary; thus 71, 85, and 81 food items entered the analysis in Delhi, Trivandrum, and Mumbai, respectively. Each of the food items were adjusted for total energy intake using a caloric density approach (each individual's food item frequency was divided by their total energy intake value). Then, by region and gender each energyadjusted value was standardized to a mean of zero and a standard deviation of one (Z-score). In the initial analysis, each of the energy-adjusted and standardized frequency variables entered the principal components or factor analysis (PROC FACTOR; SAS version 9.2; SAS Institute Inc., Cary, NC) allowing up to six factors per region. Following evaluation of scree plots, eigenvalues, the proportion of explained factor variance, and overall interpretability, we retained the first two components from the initial analysis for each region. In the final analyses limited to two components per region, we rotated each factor using the VARIMAX option in PROC FACTOR to obtain an orthogonal solution. For each subject within a region, we calculated factor scores for each of the rotated factors by summing the frequency of consumption multiplied by the factor loadings across all food items in that region. Mean scores for each of the region-specific primary and secondary factors were categorized into sex-specific tertiles. Thus, for each regional factor or dietary pattern, the highest tertile represents persons whose diets conformed most closely to

\begin{tabular}{|c|c|c|}
\hline $\begin{array}{l}\text { Food } \\
\text { groups }\end{array}$ & Reference groups & Food items \\
\hline Example: & $\begin{array}{l}\text { Example of reference } \\
\text { groups for rice: }\end{array}$ & $\begin{array}{l}\text { Examples of food items for the } \\
\text { reference group "plain rice": }\end{array}$ \\
\hline \multirow[t]{8}{*}{ Rice } & Plain rice & Basmati rice \\
\hline & Fermented rice & White-milled rice \\
\hline & $\begin{array}{l}\text { Fermented rice dish } \\
\text { with }\end{array}$ & Brown rice \\
\hline & Pulses & Rice Bhakri \\
\hline & $\begin{array}{l}\text { Plain rice dish with } \\
\text { pulses }\end{array}$ & Oratti \\
\hline & Mixed rice dish & Kanji Rice \\
\hline & & Puttu \\
\hline & & Idiappam \\
\hline
\end{tabular}

that particular pattern (highest concordance) and the referent or lowest category represents the lowest concordance. Factor names were defined by carefully examining factor loadings for food items, as well as Spearman correlations for dietary patterns with broader food groups (e.g., total rice, total wheat, total fruit, etc.; Table 1) and macronutrients. We also examined factor analyses in men and women separately, but the dietary patterns were found to be nearly identical to each other and to the combined results presented.

Using multiple logistic regression, we investigated cross-sectional associations between dietary patterns and cardio-metabolic markers of risk, including abdominal adiposity, impaired fasting blood glucose (pre-diabetes), dyslipidemia, diabetes, and hypertension. Multivariate models were adjusted for the following covariates (categories defined in Table 2): age (continuous), gender, education, income, religion, marital status, history of tobacco use, history of alcohol use, and physical activity (modeled in region and gender-specific tertiles). We evaluated multivariate models with and without a continuous covariate for total energy intake [36,37]. Inclusion of total energy intake tended to attenuate the effect estimates; thus, the more conservative, adjusted results are presented. If necessary to prevent issues with model fit, variable categories with small cells in some of the regions were collapsed [e.g., religion (Hindu/other), income (high/ low), education (high/low), tobacco use (any/none)]. Adjustment for other prevalent chronic conditions (e.g., diabetes models adjusted for hypertension and/or dislipidemia, abdominal adiposity models adjusted for diabetes and/or hypertension, etc.) did not appreciably change the estimates. $P$ values for linear trend were estimated by creating a continuous variable using the sex-specific median value within tertiles. We did not find any evidence of effect modification by gender. All statistical tests were considered statistically significant when two-sided $P<0.05$. All analyses were conducted in SAS version 9.2 (SAS Institute Inc., Cary, NC).

\section{Results}

Table 2 presents the characteristics of the India Health Study participants by region. Delhi had the greatest proportion of participants with higher education and income. Based on BMI alone, approximately half of the participants across the regions were overweight or obese, while $80-90 \%$ met the criteria for abdominal adiposity. By gender (data not shown), $4 \%$ of women and $6 \%$ of men had a BMI $<18.5$, while $20 \%$ of women and $6 \%$ of men had a BMI $\geq 30$ [25]. Across the regions, the prevalence of hypertension ranged from 46 to $51 \%$ and the prevalence of diabetes ranged from 10 to $28 \%$. In Delhi, participants had the lowest physical activity levels and more than half were dyslipidemic. In Trivandrum, 
Table 2 Characteristics of India Health Study participants who completed Diet and Medical Histories

\begin{tabular}{|c|c|c|c|}
\hline Characteristic & $\begin{array}{c}\text { Delhi } \\
n=824\end{array}$ & $\begin{array}{c}\text { Trivandrum } \\
n=2,247\end{array}$ & $\begin{array}{l}\text { Mumbai } \\
n=743\end{array}$ \\
\hline \multicolumn{4}{|l|}{ Age distribution, yrs } \\
\hline 35 to 39 & 32 & 21 & 16 \\
\hline 40 to 49 & 31 & 33 & 31 \\
\hline 50 to 59 & 23 & 29 & 31 \\
\hline 60 to 69 & 14 & 17 & 22 \\
\hline Female, $\%$ & 53 & 50 & 52 \\
\hline \multicolumn{4}{|l|}{ Highest education attained, $\%$} \\
\hline Middle school & 34 & 44 & 38 \\
\hline Secondary school & 27 & 46 & 56 \\
\hline University & 39 & 10 & 5 \\
\hline Married, $\%$ & 94 & 93 & 81 \\
\hline \multicolumn{4}{|l|}{ Household monthly income, INR,\% } \\
\hline$<5,000$ & 6 & 69 & 36 \\
\hline $5,000-10,000$ & 18 & 27 & 45 \\
\hline$>10,000$ & 76 & 4 & 19 \\
\hline \multicolumn{4}{|l|}{ Primary religion, $\%$} \\
\hline Hindu & 77 & 34 & 57 \\
\hline Muslim & 3 & 34 & $<1$ \\
\hline Christian & $<1$ & 32 & 5 \\
\hline Other (Sikh, Buddhist, Jain) & 20 & $<1$ & 38 \\
\hline \multicolumn{4}{|l|}{ History of tobacco use } \\
\hline None & 81 & 73 & 50 \\
\hline Smokeless (chewing, snuff, betel) & 3 & 5 & 44 \\
\hline Smoke (cigarettes, bidi, hukka) & 16 & 22 & 6 \\
\hline \multicolumn{4}{|l|}{ History of alcohol use } \\
\hline No & 79 & 85 & 79 \\
\hline Yes & 21 & 16 & 21 \\
\hline Physical activity, MET-hr/wk* & $42.8(45.6)$ & $153.2(107.9)$ & $179.1(141.5)$ \\
\hline Obesity $^{\dagger}, \%$ & 56 & 49 & 46 \\
\hline Abdominal adiposity ${ }^{\S}, \%$ & 92 & 90 & 86 \\
\hline Dyslipidemia ${ }^{*}, \%$ & 56 & - & - \\
\hline Diabetes ${ }^{f} \%$ & 18 & 28 & 10 \\
\hline Medical history & 10 & 17 & 10 \\
\hline Fasting plasma glucose test $\geq 126 \mathrm{mg} / \mathrm{dl}$ & 8 & 11 & - \\
\hline Hypertension ${ }^{\neq}, \%$ & 47 & 51 & 46 \\
\hline Medical history & 18 & 16 & 20 \\
\hline $\mathrm{SBP} \geq 140 \mathrm{mmHg}$ or $\mathrm{DBP} \geq 90 \mathrm{mmHg}$ & 29 & 35 & 26 \\
\hline \multicolumn{4}{|l|}{ Dietary intake, $\%$ of total energy* } \\
\hline Fat & $41.1(4.9)$ & $23.3(5.8)$ & $39.7(5.3)$ \\
\hline Carbohydrate & $48.2(5.4)$ & $60.5(6.2)$ & $47.3(5.4)$ \\
\hline Protein & $12.1(1.6)$ & $15.0(2.2)$ & $13.7(2.1)$ \\
\hline
\end{tabular}

Abbreviations: INR, Indian Rupee; MET, metabolic equivalents of task. All estimates exclude missing data..

*Presented as mean and standard deviation (SD).

${ }^{\dagger}$ Body mass index $\geq 25 \mathrm{~kg} / \mathrm{m}^{2}$; WHO universal cutpoint for overweight and suggested Asian-specific cut-point for obesity.

${ }^{\text {s } W a i s t-t o-h i p ~ r a t i o ~} \geq 0.90 \mathrm{~cm}$ in males or $0.80 \mathrm{~cm}$ in females.

${ }^{¥} \mathrm{HDL}<40 \mathrm{mg} / \mathrm{dl}$ in males or $50 \mathrm{mg} / \mathrm{dl}$ in females, triglycerides $>200 \mathrm{mg} / \mathrm{dl}$, total cholesterol to HDL ratio $\geq 5$.

$\int$ Positive medical history (self-report) with current medication use or fasting plasma glucose $\geq 126 \mathrm{mg} / \mathrm{dl}$.

$\neq$ Positive medical history (self-report) with current medication use or SBP $\geq 140 \mathrm{mmHg}$ or DBP $\geq 90 \mathrm{mmHg}$. 
participants appeared to consume a lower proportion of fat and higher proportion of carbohydrate than participants in Delhi or Mumbai. However, the distribution of macronutrients within each region did not vary substantially across tertiles of dietary patterns (Additional file 1: Appendix). Across all regions, concordance with dietary patterns across tertiles of mean factor scores did appear to differ quite markably with levels of physical activity, income, and education (Additional file 1: Appendix).

Table 3 shows the main results of the factor analysis and presents for each region the two retained factors and top loading food items defining each dietary pattern. Table 4 presents correlations between nutrient intakes, broader food groups, and dietary patterns within each region. In Delhi, the primary pattern, which we called "fruit-dairy," included fruit, fruit juice, and mixed dishes likely to contain cheese, yogurt, or other types of dairy. It was most strongly correlated with total fruit $(\mathrm{r}=0.55)$, total dairy $(r=0.51)$, calcium, and cholesterol intake $(r>0.20)$. The secondary pattern in Delhi, "vegetables-pulses," was positively correlated with total vegetables $(\mathrm{r}=0.46)$, total pulses $(r=0.32)$, total fat $(r=0.22)$, and retinol intake $(r=$ $0.46)$, but inversely correlated with rice, meat, and protein intake $(r<-0.20)$. In Trivandrum the "pulses-rice" pattern was defined by top loading food items or mixed dishes composed mainly of pulses and fermented rice (Table 3 ). This pattern was also inversely correlated with intakes of iron, calcium, retinol, and total fish (Table 4). The top loading items for the secondary "sweets-snacks" pattern in Trivandrum were mainly sweet and fried savory snacks (Table 3). This pattern was also positively correlated with fat, cholesterol, and retinol intake ( $r \geq 0.37)$, as shown in Table 4. In Mumbai, the primary "fruit-vegetables" pattern was the most strongly correlated with total vegetables and total fruit $(\mathrm{r}=0.72)$, as well as calcium, iron, and retinol intake. The "snacks-meat" pattern in Mumbai was strongly correlated with intake of cholesterol $(r=0.57)$, meat $(\mathrm{r}=0.46)$, and sweets $(\mathrm{r}=0.32)$.

Multivariate-adjusted associations for dietary patterns with abdominal adiposity, hypertension, and diabetes

Table 3 Top 10 loading food items* for primary and secondary factors by region, India Health Study

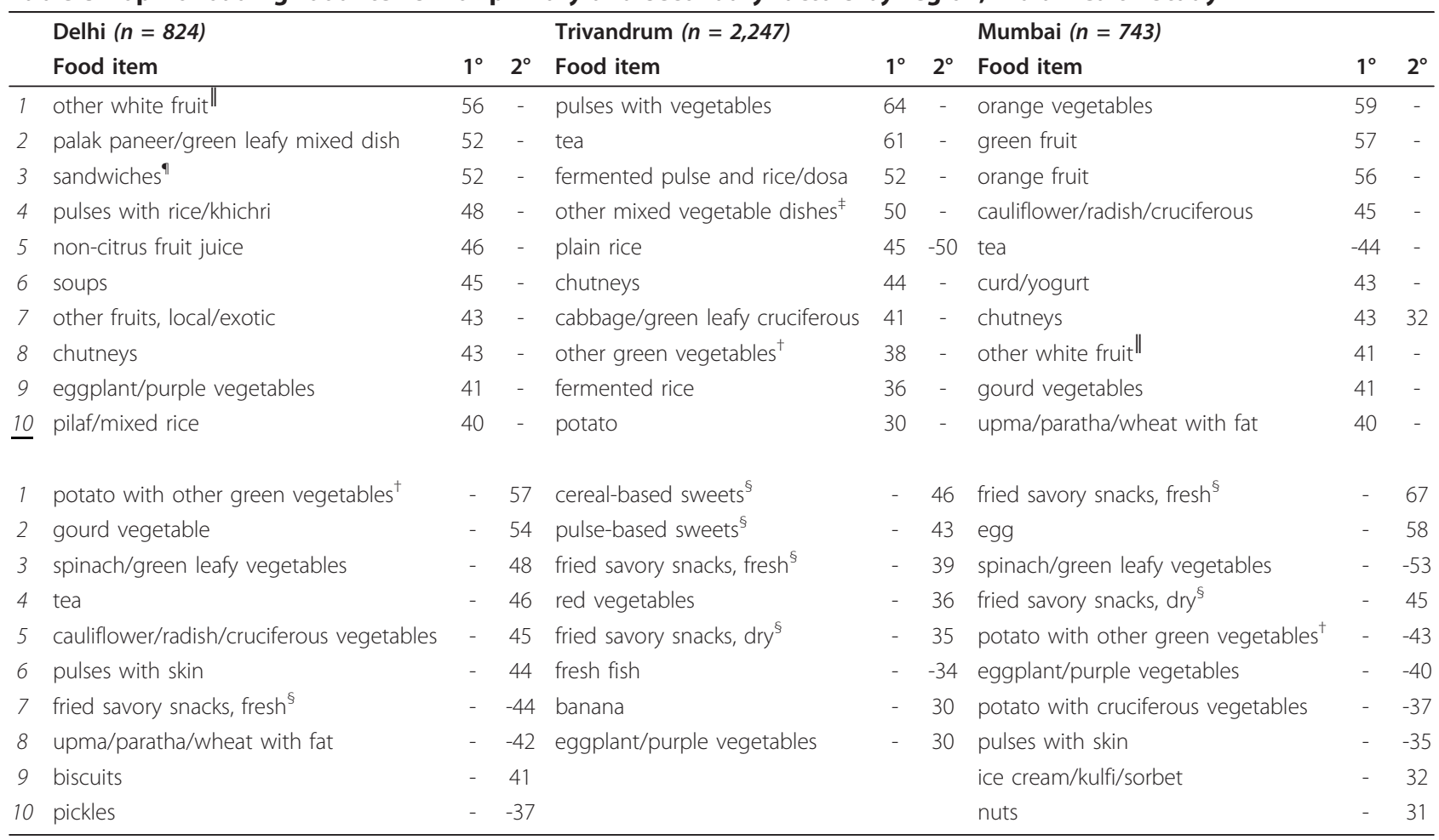

$\mathrm{N}=824 ; 2,247 ; 743$ in Delhi, Trivandrum, and Mumbai, respectively.

* Rotated factor pattern; values (correlation coefficients) are multiplied by 100 and rounded to the nearest integer; top factor loadings ( $\geq|30|)$ for food items are presented; factor loadings $<30$ are not shown for simplicity.

"other than banana (e.g., lichi, pear, guava, musk melon, quince).

"not including hamburgers/fast-food, e.g., vegetable, chicken, or cheese sandwiches;

${ }^{\dagger}$ other than leafy or cruciferous (e.g., peas, capsicum, ladies finger).

${ }^{\ddagger}$ vegetable curries and stews (e.g., avial, theeyal).

${ }^{5}$ Indian snacks/sweets: fresh fried savory (e.g., vada, samosa); dry fried savory (e.g., murukku, fruit chips); non-fried savory (e.g., vegetable puff, mince pie, dhokla); cereal-based sweet (e.g., halwa, rice puttu, diwali); milk-based sweet (e.g., custard, khoa); pulse-based sweet (e.g., ladoo, puran poli); fruit/vegetable-based sweet (e.g., carrot/gourd halwa, fried bananas). 
Table 4 Spearman correlations of the mean factor scores for regional dietary patterns with nutrients and food groups, India Health Study

\begin{tabular}{|c|c|c|c|c|c|c|}
\hline & \multicolumn{2}{|r|}{ Delhi } & \multicolumn{2}{|c|}{ Trivandrum } & \multicolumn{2}{|c|}{ Mumbai } \\
\hline & $\begin{array}{c}\text { Factor } 1 \\
\text { fruit - dairy }\end{array}$ & $\begin{array}{c}\text { Factor } 2 \\
\text { vegetables - pulses }\end{array}$ & $\begin{array}{c}\text { Factor } 1 \\
\text { pulses - rice }\end{array}$ & $\begin{array}{c}\text { Factor } 2 \\
\text { sweets - snacks }\end{array}$ & $\begin{array}{c}\text { Factor } 1 \\
\text { fruit - vegetables }\end{array}$ & $\begin{array}{c}\text { Factor } 2 \\
\text { snacks - meat }\end{array}$ \\
\hline \multicolumn{7}{|l|}{ Nutrient intake } \\
\hline protein,\% TEI & NS & -0.24 & NS & -0.19 & -0.11 & 0.25 \\
\hline carbohydrate,\% TEI & 0.18 & -0.13 & -0.25 & -0.31 & NS & NS \\
\hline fat,\% TEl & -0.18 & 0.22 & 0.32 & 0.48 & NS & -0.16 \\
\hline cholesterol, mg & 0.24 & 0.14 & -0.19 & 0.38 & 0.24 & 0.57 \\
\hline calcium, mg & 0.23 & 0.09 & -0.26 & 0.34 & 0.61 & 0.18 \\
\hline iron, mg & -0.24 & 0.17 & -0.60 & 0.20 & 0.55 & 0.25 \\
\hline retinol equivalents, mcg & -0.08 & 0.46 & -0.28 & 0.37 & 0.35 & NS \\
\hline \multicolumn{7}{|l|}{ Food group, frequency } \\
\hline total rice & NS & -0.23 & NS & -0.07 & 0.34 & NS \\
\hline total wheat & -0.08 & 0.18 & -0.12 & 0.42 & 0.21 & 0.20 \\
\hline total vegetables ${ }^{\dagger}$ & 0.08 & 0.46 & 0.08 & 0.52 & 0.72 & -0.15 \\
\hline total potatoes & 0.09 & 0.08 & -0.10 & 0.10 & 0.35 & NS \\
\hline total pulses & -0.53 & 0.32 & 0.26 & 0.23 & 0.35 & 0.20 \\
\hline total fruit & 0.55 & 0.22 & -0.16 & 0.43 & 0.72 & 0.12 \\
\hline total dairy & 0.51 & -0.09 & 0.10 & 0.34 & 0.51 & 0.16 \\
\hline total fish & -0.19 & -0.21 & -0.43 & -0.07 & 0.17 & 0.32 \\
\hline total meat & 0.12 & -0.21 & -0.20 & 0.32 & 0.10 & 0.46 \\
\hline total sweets & -0.09 & -0.10 & -0.19 & 0.50 & 0.39 & 0.32 \\
\hline
\end{tabular}

$\mathrm{N}=824 ; 2,247 ; 743$ in Delhi, Trivandrum, and Mumbai, respectively.

Abbreviations: TEl, total energy intake; NS, not statistically significant.

${ }^{\dagger}$ not including potatoes.

All $P<0.01$ unless otherwise specified as not significant (NS) for multiple comparisons.

within each region are presented in Table 5. In Delhi, the fruit and dairy pattern was positively associated with both abdominal adiposity and hypertension, but not associated with diabetes or dyslipidemia (not shown). No associations were found for the secondary pattern in Delhi. In Trivandrum, the pulses and rice pattern was inversely associated with diabetes (IFG $\geq 126 \mathrm{mg} / \mathrm{dl}$ ) and/ or pre-diabetes [IFG $\geq 100 \mathrm{mg} / \mathrm{dl}$; OR and $95 \%$ CI for highest versus lowest tertile, 0.69 (0.52-0.92); $\mathrm{P}$ trend = 0.01; data presented in text only]. The sweets and snacks pattern was positively associated with abdominal adiposity [OR and 95\% CI: 2.05 (1.34-3.14); P trend $=0.03$ ] and pre-diabetes [IFG $\geq 100 \mathrm{mg} / \mathrm{dl}$; OR and $95 \% \mathrm{CI}$ for highest versus lowest tertile, 1.20 (0.94-1.53); $\mathrm{P}$ trend $=0.16$; data presented in text only], but not associated with diabetes (IFG $\geq 126$ ) or hypertension. In Mumbai, the fruit and vegetables pattern was inversely associated with hypertension, while the snack and meat pattern appeared to be positively associated with abdominal adiposity [OR and 95\% CI: 1.61 (0.96-2.71); P trend $=0.09$ ].

In the largest study region, Trivandrum, we conducted a sensitivity analysis (data presented in text only) comparing dietary patterns associations in participants with normal blood glucose ( $<100 \mathrm{mg} / \mathrm{dl} ; \mathrm{n}=661$; referent group) to each of the following: prediabetics $(100-125 \mathrm{mg} / \mathrm{dl}$; $\mathrm{n}=407)$, untreated diabetics $(\geq 126 \mathrm{mg} / \mathrm{dl} ; \mathrm{n}=232)$, and treated diabetics (valid prescription medication for managing blood sugar; $n=252$ ). The pulses and rice pattern was most strongly inversely associated with treated diabetes [multivariate-adjusted OR and 95\% CI, highest to lowest tertile: 0.54 (0.33-0.89); P trend $=0.02$ ]. Conversely, the snack and meat pattern was positively associated with treated diabetes [(1.00 (ref), 1.69 (1.11-2.56), 1.76 $(1.12-2.75) ; \mathrm{P}$ trend $=0.02]$.

\section{Discussion}

In each of the study regions two dietary patterns emerged and varied associations with cardio-metabolic risk factors were observed. In cross-sectional analyses adjusted for key demographic and lifestyle confounders, diets across all regions characterized by dairy, fried snacks, and sweets appeared to be positively asssociated with abdominal adiposity. Conversly, dietary patterns in Trivandrum and Mumbai, characterized by intake of vegetables and pulses, were inversely related to diabetes and hypertension.

South Asians in India, and throughout the world, are an important population to study due to their greatly elevated risk of diabetes and cardiovascular disease $[38,39]$. However, compared to the breadth of studies on 
Table 5 Multivariate-adjusted associations of regional dietary patterns with abdominal adiposity, hypertension, and diabetes status, India Health Study

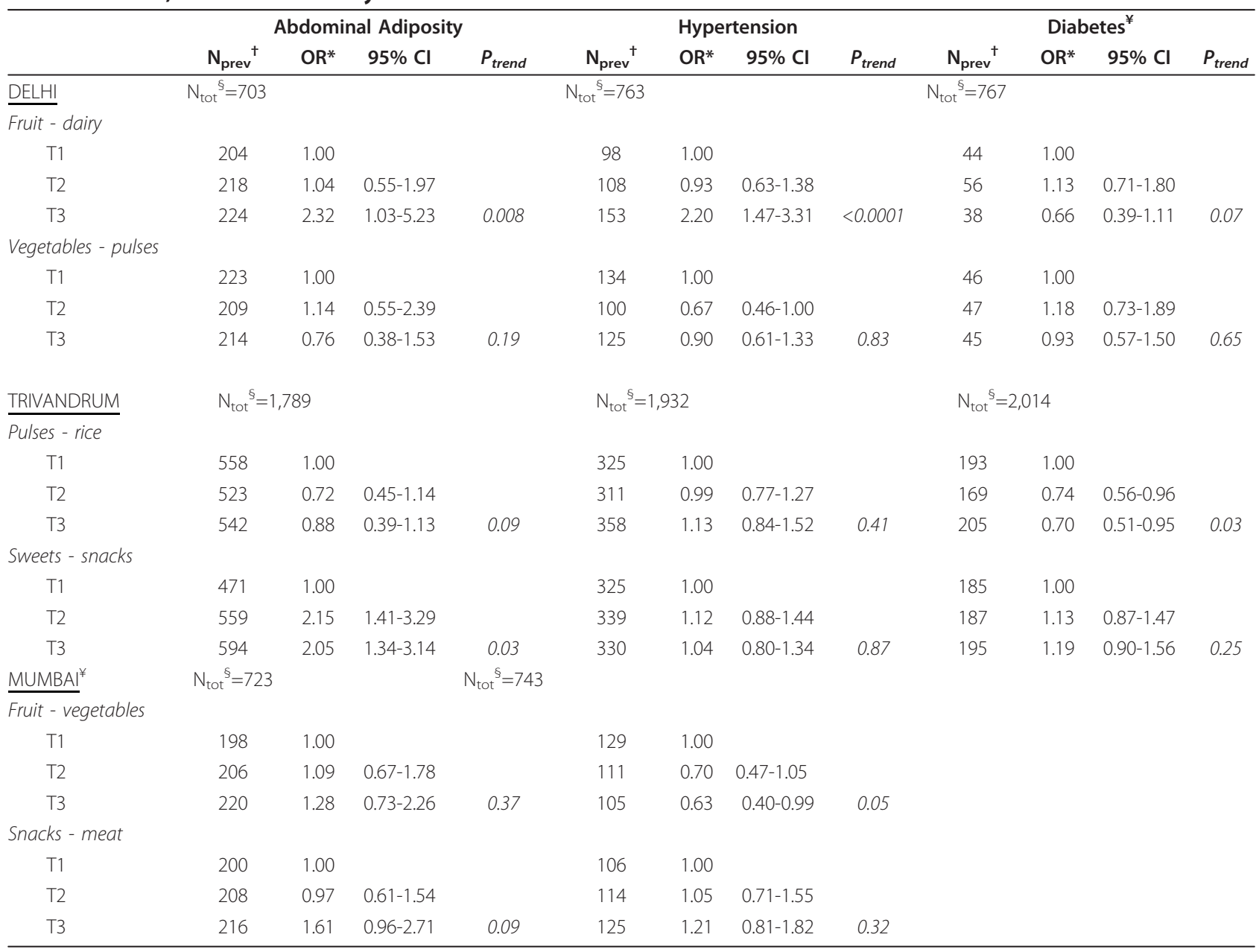

Abbreviations: $\mathrm{OR}$, odds ratio; $\mathrm{Cl}$, confidence interval; $\mathrm{T}$, tertile.

${ }^{5}$ Total number in each region; missing excluded from analysis.

${ }^{\dagger}$ Number of participants who have condition within each sex-specific tertile of dietary pattern concordance.

*Multivariate adjustment for age, gender, education, income, marital status, tobacco and alcohol use, religion, physical activity, total energy intake.

${ }^{*}$ No fasting blood collected in Mumbai.

Western-style dietary patterns and chronic disease etiology $[14,40]$, few studies have examined food patterns in the high-risk Indian population $[13,16,18,41-43]$ or collected biological samples. Compared to Caucasian populations, South Asians typically develop metabolic syndromes at lower BMIs, and are known to have increased visceral fat and insulin resistance $[3,44]$. Abdominal adiposity, impaired glucose and lipid levels, as well as hypertension in a high-proportion of study participants corresponds with the high-risk "Asian Indian phenotype" that may be a product of genetic adaptations to food insecurity, fetal or early childhood malnutrition, as well as more recent environmental exposures including adult diet [2,18,44-49].

High fat intake ( $40 \%$ of total energy intake), particularly in Delhi and Mumbai, was one indication that components of the Indian diet may be contributing to a high-risk diet and health profile. However, we found little evidence of Westernization of the diet [50] through food items, such as red meat, sweetened beverages, and processed or fast foods, but did observe other characteristics such as sugary and high-fat foods perhaps reflecting a transitional diet arising from access to cheap oils and sweeteners [8]. Top loading food items for the dietary patterns included fruit, vegetables, chutneys, and tea, as well as traditional Indian fried snacks and desserts. Across all regions, dietary patterns frequently contained traditional mixed dishes composed mainly of vegetables, pulses, cereals and/or potato, but there were regional differences in the types of cereals (e.g., fermented rice, plain rice, wheat products) and potential protein sources such as pulses, dairy, and eggs. A study conducted in the 1970's among Indian physicians [51,52], 
reported a very low-fat, rice and pulse-based diet in the South. This contrasted with a high-fat, wheat-based diet in the North with frequent consumption of vegetables cooked in ghee, milk, and yogurt. More recently, dietary data collected in India from women in the National Family Health Survey (NFHS-2) [17] also found that intake of animal foods (eggs, dairy, fish, and meat) varied across the different regions [16]. Compared to China and other Asian countries, high amounts of sugar are consumed in India [9]. Our analysis suggests a continued preference for the traditional Indian sweets, as opposed to Western desserts (cake, pies, candy, etc.) which may be more easily recognized as unhealthy [53]. In addition to sugar, many of these Indian sweets are often prepared with a substantial amount of saturated fat from ghee or coconut components.

Previous studies have reported that cardiovascular disease risk in India is likely to be inversely associated with intake of fruits, vegetables, and mustard oil $[12,43]$; and positively associated with intake of refined carbohydrates and unhealthy fats (reviewed in $[18,54]$ ). In Trivandrum we found that the more traditional pulses and rice pattern was inversely associated with diabetes. Similarly, the more prudent-appearing fruit and vegetable pattern in Mumbai was inversely associated with hypertension. Secondary patterns in both of these regions, characterized by intake of fried snacks and sweets, appeared to be positively associated with abdominal adiposity. In Delhi, the northern-most region, where dietary patterns appeared to reflect access to a greater variety of foods, the predominant fruit and dairy pattern was positively associated with both abdominal adiposity and hypertension. Although one may not typically consider fruit part of a high-risk diet, higher concordance with this pattern was more common among participants of higher socio-economic status and lower physical activity and may also reflect dietary choices or substitutions to manage a chronic condition. Unlike Trivandrum and Mumbai, the vegetables and pulses pattern in Delhi, was not associated with any chronic conditions and we found no associations for dietary patterns and dyslipidemia.

The relationship between diet and chronic disease risk is certainly complex and we are likely to encounter unfamiliar challenges in the Indian diet. The type, as well as the cooking, of vegetables (green leafy, starchy, stir-fried, stewed, boiled, etc.) in traditional Indian mixed dishes may alter some of their preventive properties [12,55-57] and may also contribute substantially to added fat $[51,58]$. The contrasting correlations we observed between intakes of iron, calcium, and retinol and the more traditional patterns in Trivandrum versus Mumbai, suggest that the nutrient quality of these regional diets vary considerably. Other cross-sectional studies in South Asian populations, living in India and abroad, have suggested that characteristically high fruit and vegetable intake may be associated with lower LDL and total cholesterol [43], but that high-carbohydrate diets, overall, may be associated with higher triglycerides and lower HDL cholesterol $[59,60]$, as well as hyperinsulinemia [61] in South Asians. Unraveling the nutrient composition of specific Indian foods [41], particularly the fatty acid, sodium, and glycemic composition [58], as well as the complex relationship between diet, socioeconomic status, obesity, and chronic disease risk [62] is likely to be of great relevance for India.

Major strengths of our study were the use of interviewer-administered questionnaires developed specifically for the study, collection of fasting blood, and measurement of anthropometry and blood pressure by trained medical staff. Fasting blood and blood pressure measurements, along with medication use, were invaluable in classifying diabetes and hypertension status, as self-reports were clearly an underestimate of the prevalence in this population. However, the external validity of our findings may be limited in this lower to upper middle class sample with very high rates of abdominal adiposity and obesity. As with many developing countries, a moderate improvement in socio-economic status is likely to increase access to both over-nutrition and a sedentary lifestyle; thus, affluence may serve as a key risk factor for obesity, diabetes, and other related conditions [63]. Other large cross-sectional studies have observed a double burden of under- and over-weight [17,64-66] and throughout India, nutritional status and chronic disease risk profiles vary substantially by intraand inter-state socio-economic extremes [67-69]. The prevalence of cardio-metabolic risk factors we observed more closely resembled studies of middle-aged adults residing in metropolitan areas of India $[70,71]$ and that of South Asians residing in the U.S. [72]. However, it also plausible that recruitment of IHS participants from households may have resulted in a clustering of risk factors [73].

We recognize the limitations of the cross-sectional study design to make strong conclusions regarding causality and chronic disease etiology. Dietary patterns identified by factor analysis are intended to represent the actual eating patterns that arose from the study sample, but do not necessarily capture optimal diets or unhealthy extremes that one may want to specifically target for intervention or prevention. Factor analysis also involves some level of subjectivity in selecting and grouping food items. However, in our case, a trained nutritionist in India grouped all the food items collected in the DH into meaningful subgroups prior to the patterns analysis. In addition to the number and composition of the food items, various statistical options and methods for factor analysis, as well as the selection of 
the number of factors to retain in the final analysis, may also affect the overall explained factor variance [74]. Although we used standard methods and a priori grouped food items, the detailed DH and large number of food items collected [75] may have limited variation explained by the dietary patterns $(8-12 \%$ within each region), as well as overall interpretability. Although our variance estimates exceeded those from analyses in similarly underserved populations [76], some larger U.S. cohort studies achieved total explained variance levels as high as 20 to $30 \%$ [35,77]. Dietary patterns analysis conducted in some Western cohorts may also have benefitted from a larger sample size, as well as a more cohesive population with regard to ethnicity, education, and economic access to a variety of foods to meet nutritional needs and preferences.

\section{Conclusions}

Participants in all three regions primarily consumed food items that did not appear largely "unhealthy" by Western standards. More traditional dietary patterns in the southern regions, characterized by intake of vegetables and pulses, were inversely associated with the prevalence of diabetes and hypertension. However, overall anthropometric and biological measurements spanning across the majority of the study population characterized high-risk levels not usually seen in studies within the U.S. and Europe. Compelling associations between regional Indian diets and highly prevalent cardio-metabolic risk factors, such as abdominal adiposity and hypertension, suggest that many of the unique regional components of Indian diets, such as high-fat dairy, sweets and fried snacks, may be characterizing a high-risk diet. Continued investigation of diet, evaluating both quality and quantity, as well as other environmental and biological factors, will be needed to better understand the risk profile in this population and potential means of prevention.

\section{Additional material}

Additional file 1: Appendix. Distribution of participant characteristics across extreme tertiles of regional dietary patterns, India Health Study

\section{Abbreviations}

BMl: body mass index; Cl: confidence interval; DH: diet history; FFQ: Food Frequency Questionnaire; IHS: India Health Study; HDL: high density lipoprotein; IFG: impaired fasting glucose; LDL: Iow density lipoprotein; MET: metabolic equivalents of task; OR: odds ratio; TC: total cholesterol; TG: triglycerides; WHR: waist-to-hip ratio.
\end{abstract}

\section{Acknowledgements and Fundings}

This research was supported by the Intramural Research Program of the $\mathrm{NIH}$ National Cancer Institute. We are indebted to the participants of the IHS as well as Sriram Hariharan, Puneet Chadda, Mary McAdams, Eric Berger, and Sujata Dixit-Joshi.

\section{Author details}

${ }^{1}$ Division of Cancer Epidemiology and Genetics, National Cancer Institute, (6120 Executive Blvd), Rockville, MD, (20852), USA. ${ }^{2}$ Centre for Chronic Disease Control, (C1/52, Safdarjung Development Area), New Delhi, (110 016), India. ${ }^{3}$ Steno Diabetes Center, (Niels Steensens vej 8), Gentofte, (DK 2820), Denmark. ${ }^{4}$ Department of Cardiac Biochemistry, All India Institute of Medical Sciences, (Ansari Nagar), New Delhi, (110029), India. ${ }^{5}$ Regional Cancer Center, (Medical College Campus), Trivandrum, Kerala (695011), India. ${ }^{6}$ Healis Sekhsaria Institute for Public Health, (Thane, Sector 11, CBD Belapur), Navi Mumbai, (400 614), India. 'Westat, (1600 Research Blvd), Rockville, MD, (20850), USA. ${ }^{8}$ UN World Food Programme, (Via Cesare Giulio Viola, 68), Rome, (00148), Italy.

\section{Authors' contributions}

The authors' responsibilities were as follows-CRD conducted the statistical analysis, interpretation of results, and drafting of the manuscript; DP, BIG, LMF, and RS contributed to the interpretation of results and drafting of the manuscript; KK served as the study nutritionist and with RS developed the diet assessment; BIG provided statistical and methodological support; ND and PSG recruited study participants and acquired data; LR conducted laboratory analysis; HS and AM provided site-specific dietary assessment support; YS provided data management and study coordination; RS, DP, AM, PCG, NC, TR, KR conceived of the study, and participated in its design and coordination. All authors read and approved the final manuscript.

\section{Competing interests}

The authors declare that they have no competing interests.

Received: 9 September 2010 Accepted: 28 January 2011 Published: 28 January 2011

\section{References}

1. Wild S, Roglic G, Green A, Sicree R, King H: Global Prevalence of Diabetes. Diabetes Care 2004, 27(5):1047-1053.

2. Mohan V, Deepa R: Adipocytokines and the expanding 'Asian Indian Phenotype'. J Assoc Physicians India 2006, 54:685-686.

3. Enas EA, Mohan V, Deepa M, Faroog S, Pazhoor S, Chennikkara H: The metabolic syndrome and dyslipidemia among Asian Indians: a population with high rates of diabetes and premature coronary artery disease. J Cardiometab Syndr 2007, 2(4):267-275.

4. Lichtenstein AH, Appel $\sqcup$, Brands M, Carnethon M, Daniels S, Franch HA, Franklin B, Kris-Etherton P, Harris WS, Howard B, et al: Diet and Lifestyle Recommendations Revision 2006: A Scientific Statement From the American Heart Association Nutrition Committee. Circulation 2006, 114(1):82-96.

5. Schulze MB, Hu FB: Primary prevention of diabetes: what can be done and how much can be prevented? Annu Rev Public Health 2005, 26:445-467.

6. Stampfer MJ, Hu FB, Manson JE, Rimm EB, Willett WC: Primary prevention of coronary heart disease in women through diet and lifestyle. $N$ Engl J Med 2000, 343(1):16-22.

7. Rastogi T, Devesa S, Mangtani P, Mathew A, Cooper N, Kao R, Sinha R: Cancer incidence rates among South Asians in four geographic regions: India, Singapore, UK and US. Int J Epidemio/ 2008, 37(1):147-160.

8. Caballero B, Popkin BM, (eds.): The Nutrition Transition: Diet and Disease in the Developing World. Elsevier Science Academic Press; 2002.

9. Popkin BM, Horton S, Kim S, Mahal A, Shuigao J: Trends in Diet, Nutritional Status, and Diet-related Noncommunicable Diseases in China and India: The Economic Costs of the Nutrition Transition. Nutrition Reviews 2001, 59(12):379-390.

10. Shetty PS: Nutrition transition in India. Public Health Nutrition 2002, 5(1a):175-182.

11. Rastogi T, Hildesheim A, Sinha R: Opportunities for cancer epidemiology in developing countries. Nat Rev Cancer 2004, 4(11):909-917.

12. Rastogi T, Reddy KS, Vaz M, Spiegelman D, Prabhakaran D, Willett WC, Stampfer MJ, Ascherio A: Diet and risk of ischemic heart disease in India. Am J Clin Nutr 2004, 79(4):582-592.

13. Yadav K, Krishnan A: Changing patterns of diet, physical activity and obesity among urban, rural and slum populations in north India. Obes Rev 2008, 9(5):400-408.

14. Heidemann C, Schulze MB, Franco OH, van Dam RM, Mantzoros CS, Hu FB: Dietary Patterns and Risk of Mortality From Cardiovascular Disease, 
Cancer, and All Causes in a Prospective Cohort of Women. Circulation 2008, 118(3):230-237.

15. Mente A, de Koning L, Shannon HS, Anand SS: A Systematic Review of the Evidence Supporting a Causal Link Between Dietary Factors and Coronary Heart Disease. Arch Intern Med 2009, 169(7):659-669.

16. Padmadas SS, Dias JG, Willekens FJ: Disentangling women's responses on complex dietary intake patterns from an Indian cross-sectional survey: a latent class analysis. Public Health Nutrition 2006, 9(02):204-211.

17. International Institute for Population Sciences: National Family Health Survey (NFHS-2), 1998-1999. Mumbai, India and Washington, DC, USA; 2000

18. Misra A, Khurana L, Isharwal S, Bhardwaj S: South Asian diets and insulin resistance. Br J Nutr 2009, 101(4):465-473.

19. Newby PK, Tucker KL: Empirically derived eating patterns using factor or cluster analysis: a review. Nutr Rev 2004, 62(5):177-203.

20. Hu FB: Dietary pattern analysis: a new direction in nutritional epidemiology. Curr Opin Lipidol 2002, 13(1):3-9.

21. National Cancer Registry Program: Consolidated Report of PopulationBased Cancer Registries 2001-2004. Bangalore: Indian Council of Medical Research; 2006.

22. Gupta PC, Mehta HC: Cohort study of all-cause mortality among tobacco users in Mumbai, India. Bull World Health Organ 2000, 78(7):877-883.

23. Zakaria I, Sabry L, Rizek R: Food composition tables for the near east. Food and Agricultural Organization of the United Nations and the US Department of Agriculture cooperative project 1982, 275.

24. Subar AF, Midthune D, Kulldorff M, Brown CC, Thompson FE, Kipnis V, Schatzkin A: Evaluation of alternative approaches to assign nutrient values to food groups in food frequency questionnaires. Am J Epidemiol 2000, 152(3):279-286

25. World Health Organization: Expert Consultation: Appropriate body-mass index for Asian populations and its implications for policy and intervention strategies. The Lancet 2004, 363(9403):157-163.

26. Lear SA, James PT, Ko GT, Kumanyika S: Appropriateness of waist circumference and waist-to-hip ratio cutoffs for different ethnic groups. Eur J Clin Nutr 2010, 64(1):42-61.

27. Macfarlane DJ, Lee CC, Ho EY, Chan KL, Chan DT: Reliability and validity of the Chinese version of IPAQ (short, last 7 days). J Sci Med Sport 2007, 10(1):45-51.

28. Craig CL, Marshall AL, Sjostrom M, Bauman AE, Booth ML, Ainsworth BE, Pratt M, Ekelund U, Yngve A, Sallis JF, et al: International physical activity questionnaire: 12-country reliability and validity. Med Sci Sports Exerc 2003, 35(8):1381-1395.

29. Ainsworth BE, Haskell WL, Whitt MC, Irwin ML, Swartz AM, Strath SJ, O'Brien WL, Bassett DR Jr, Schmitz KH, Emplaincourt PO, et al: Compendium of physical activities: an update of activity codes and MET intensities. Med Sci Sports Exerc 2000, 32(9 Suppl):S498-504.

30. Lott JA, Turner K: Evaluation of Trinder's Glucose Oxidase Method for Measuring Glucose in Serum and Urine. Clin Chem 1975, 21(12):1754-1760.

31. Friedewald WT, Levy Rl, Fredrickson DS: Estimation of the Concentration of Low-Density Lipoprotein Cholesterol in Plasma, Without Use of the Preparative Ultracentrifuge. Clin Chem 1972, 18(6):499-502.

32. American Diabetes Association: Diagnosis and Classification of Diabetes Mellitus. Diabetes Care 2006, 29(suppl 1):s43-s48.

33. The Expert Committee on the Diagnosis and Classification of Diabetes Mellitus: Follow-up Report on the Diagnosis of Diabetes Mellitus. Diabetes Care 2003, 26(11):3160-3167.

34. National Heart Lung and Blood Institute: Third Report of the National Cholesterol Education Program (NCEP) Expert Panel on Detection, Evaluation, and Treatment of High Blood Cholesterol in Adults (Adult Treatment Panel III) Final Report. Circulation 2002, 106(25):3143.

35. Flood A, Rastogi T, Wirfalt E, Mitrou PN, Reedy J, Subar AF, Kipnis V, Mouw T, Hollenbeck AR, Leitzmann M, et al: Dietary patterns as identified by factor analysis and colorectal cancer among middle-aged Americans. Am J Clin Nutr 2008, 88(1):176-184.

36. Willett W: Nutritional Epidemiology. Oxford: Oxford University Press; Second 1998.

37. Northstone K, Ness AR, Emmett PM, Rogers IS: Adjusting for energy intake in dietary pattern investigations using principal components analysis. Eur J Clin Nutr 2008, 62(7):931-938.

38. Oza-Frank R, Ali MK, Vaccarino V, Narayan KM: Asian Americans: diabetes prevalence across U.S. and World Health Organization weight classifications. Diabetes Care 2009, 32(9):1644-1646.
39. Stephenson R, Argeseanu S, Oza-Frank R, Hutcheson M, Narayan KM: Cardiometabolic risk among the foreign-born population in the United States: new pathways for innovative research and health policy. Ethn Dis 2008, 18(3):277.

40. van Dam RM, Rimm EB, Willett WC, Stampfer MJ, Hu FB: Dietary patterns and risk for type 2 diabetes mellitus in U.S. men. Ann Intern Med 2002, 136(3):201-209.

41. Rao PV: Dietary patterns and glucose intolerance among rural Indian populations. J Indian Med Assoc 2002, 100(3):137-140.

42. Radhika G, Sathya RM, Ganesan A, Saroja R, Vijayalakshmi P, Sudha V, Mohan V: Dietary profile of urban adult population in South India in the context of chronic disease epidemiology (CURES ? 68). Public Health Nutrition 2010, First View:1-8.

43. Radhika G, Sudha V, Mohan Sathya R, Ganesan A, Mohan V: Association of fruit and vegetable intake with cardiovascular risk factors in urban south Indians. British Journal of Nutrition 2008, 99(02):398-405.

44. Misra A, Misra R: Asian indians and insulin resistance syndrome: global perspective. Metab Syndr Relat Disord 2003, 1(4):277-283.

45. Lakshmy R, Fall CHD, Sachdev HS, Osmond C, Prabhakaran D, Biswas SD, Tandon N, Ramji S, Reddy KS, Barker DJP, et al: Childhood body mass index and adult pro-inflammatory and pro-thrombotic risk factors: data from the New Delhi birth cohort. Int J Epidemiol 2010, July 26 [Epub].

46. Raji A, Seely EW, Arky RA, Simonson DC: Body fat distribution and insulin resistance in healthy Asian Indians and Caucasians. J Clin Endocrinol Metab 2001, 86(11):5366-5371.

47. Luthra K, Bharghav B, Chabbra S, Das N, Misra A, Agarwal DP, Pandey RM Srivastava LM: Apolipoprotein E polymorphism in Northern Indian patients with coronary heart disease: phenotype distribution and relation to serum lipids and lipoproteins. Mol Cell Biochem 2002, 232(1-2):97-102.

48. Yajnik CS: The lifecycle effects of nutrition and body size on adult adiposity, diabetes and cardiovascular disease. Obesity Reviews 2002, 3(3):217-224.

49. Mente A, Razak F, Blankenberg S, Vuksan V, Davis AD, Miller R, Teo K, Gerstein H, Sharma AM, Yusuf S, et al: Ethnic Variation in Adiponectin and Leptin Levels and Their Association With Adiposity and Insulin Resistance. Diabetes Care 2010, 33(7):1629-1634.

50. Cordain L, Eaton SB, Sebastian A, Mann N, Lindeberg S, Watkins BA, O'Keefe $J \mathrm{H}$, Brand-Miller J: Origins and evolution of the Western diet: health implications for the 21st century. Am J Clin Nutr 2005, 81(2):341-354.

51. Malhotra S: Diabetes mellitus in Indian male railway doctors from south and north of India and in migrants with special reference to causation. J Assoc Physicians India 1973, 21:661-670.

52. Malhotra SL: Geographical aspects of acute myocardial infarction in India with special reference to patterns of diet and eating. Br Heart J 1967, 29(3):337-344

53. Lawton J, Ahmad N, Hanna L, Douglas M, Bains H, Hallowell N: We should change ourselves, but we can't: accounts of food and eating practices amongst British Pakistanis and Indians with type 2 diabetes. Ethnicity \& Health 2008, 13(4):305-319.

54. Mohan V, Radhika G, Vijayalakshmi P, Sudha V: Can the diabetes/ cardiovascular disease epidemic in India be explained, at least in part, by excess refined grain (rice) intake? Indian J Med Res 2010, 131(March):369-372.

55. Jiménez-Monreal AM, García-Diz L, Martínez-Tomé M, Mariscal M, Murcia MA: Influence of Cooking Methods on Antioxidant Activity of Vegetables. Journal of Food Science 2009, 74(3):H97-H103.

56. Khanum F, Siddalinga Swamy M, Sudarshana Krishna KR, Santhanam K, Viswanathan KR: Dietary fiber content of commonly fresh and cooked vegetables consumed in India. Plant Foods Hum Nutr 2000, 55(3):207-218

57. Gupta S, Bains K: Traditional cooked vegetable dishes as important sources of ascorbic acid and beta-carotene in the diets of Indian urban and rural families. Food Nutr Bull 2006, 27(4):306-310.

58. Shi Z, Hu X, Yuan B, Hu G, Pan X, Dai Y, Byles JE, Holmboe-Ottesen G: Vegetable-rich food pattern is related to obesity in China. Int $J$ Obes 2008, 32(6):975-984.

59. Merchant AT, Anand SS, Kelemen LE, Vuksan V, Jacobs R, Davis B, Teo K, Yusuf S, SHARE ft, Investigators SHARE-AP: Carbohydrate intake and HDL in a multiethnic population. Am J Clin Nutr 2007, 85(1):225-230. 
60. Park SH, Lee KS, Park HY: Dietary carbohydrate intake is associated with cardiovascular disease risk in Korean: Analysis of the third Korea National Health and Nutrition Examination Survey (KNHANES III). International Journal of Cardiology 2010, 139(3):234-240.

61. Sevak L, McKeigue P, Marmot M: Relationship of hyperinsulinemia to dietary intake in south Asian and European men. Am J Clin Nutr 1994, 59(5):1069-1074

62. Martikainen P, Brunner E, Marmot M: Socioeconomic differences in dietary patterns among middle-aged men and women. Soc Sci Med 2003, 56(7):1397-1410.

63. Mohan V, Mathur P, Deepa R, Deepa M, Shukla DK, Menon GR, Anand K, Desai NG, Joshi PP, Mahanta J, et al: Urban rural differences in prevalence of self-reported diabetes in India-the WHO-ICMR Indian NCD risk factor surveillance. Diabetes Res Clin Pract 2008, 80(1):159-168.

64. Reddy KS, Prabhakaran D, Chaturvedi V, Jeemon P, Thankappan KR, Ramakrishnan L, Mohan BV, Pandav CS, Ahmed FU, Joshi PP, et al: Methods for establishing a surveillance system for cardiovascular diseases in Indian industrial populations. Bull World Health Organ 2006, 84(6):461-469.

65. Griffiths PL, Bentley ME: The nutrition transition is underway in India. J Nutr 2001, 131(10):2692-2700.

66. Wang Y, Chen HJ, Shaikh S, Mathur P: Is obesity becoming a public health problem in India? Examine the shift from under- to overnutrition problems over time. Obes Rev 2009, 10(4):456-474

67. Subramanian SV, Kawachi I, Smith GD: Income inequality and the double burden of under- and overnutrition in India. J Epidemiol Community Health 2007, 61(9):802-809.

68. Kinra S, Bowen LJ, Lyngdoh T, Prabhakaran D, Reddy KS, Ramakrishnan L, Gupta R, Bharathi AV, Vaz M, Kurpad AV, et al: Sociodemographic patterning of non-communicable disease risk factors in rural India: a cross sectional study. BMJ 2010, 341.

69. Reddy KS, Prabhakaran D, Jeemon P, Thankappan KR, Joshi P, Chaturvedi V, Ramakrishnan L, Ahmed F: Educational status and cardiovascular risk profile in Indians. Proc Natl Acad Sci USA 2007, 104(41):16263-16268.

70. Singh RB, Pella D, Mechirova V, Kartikey K, Demeester F, Tomar RS, Beegom R, Mehta AS, Gupta SB, De Amit K, et al: Prevalence of obesity, physical inactivity and undernutrition, a triple burden of diseases during transition in a developing economy. The Five City Study Group. Acta Cardiol 2007, 62(2):119-127.

71. Wang Y, Chen HJ, Shaikh S, Mathur P: Is obesity becoming a public health problem in India? Examine the shift from under- to overnutrition problems over time. Obesity Reviews 2009, 10(4):456-474.

72. Wang ET, de Koning L, Kanaya AM: Higher Protein Intake Is Associated with Diabetes Risk in South Asian Indians: The Metabolic Syndrome and Atherosclerosis in South Asians Living in America (MASALA) Study. J Am Coll Nutr 2010, 29(2):130-135.

73. Mohan V, Shanthirani CS, Deepa R: Glucose intolerance (diabetes and IGT) in a selected South Indian population with special reference to family history, obesity and lifestyle factors-the Chennai Urban Population Study (CUPS 14). J Assoc Physicians India 2003, 51:771-777.

74. Martinez ME, Marshall JR, Sechrest L: Invited commentary: Factor analysis and the search for objectivity. Am J Epidemiol 1998, 148(1):17-19.

75. Iqbal R, Ajayan K, Bharathi AV, Zhang X, Islam S, Soman CR, Merchant AT: Refinement and validation of an FFQ developed to estimate macro- and micronutrient intakes in a south Indian population. Public Health Nutrition 2009, 12(01):12-18.

76. Hamer M, Mishra GD: Dietary patterns and cardiovascular risk markers in the UK Low Income Diet and Nutrition Survey. Nutr Metab Cardiovasc Dis 2010, 20(7):491-497.

77. Hu FB, Rimm E, Smith-Warner SA, Feskanich D, Stampfer MJ, Ascherio A, Sampson L, Willett WC: Reproducibility and validity of dietary patterns assessed with a food-frequency questionnaire. Am J Clin Nutr 1999, 69(2):243-249.

doi:10.1186/1475-2891-10-12

Cite this article as: Daniel et al: A cross-sectional investigation of regional patterns of diet and cardio-metabolic risk in India. Nutrition Journal 2011 10:12.

\section{Submit your next manuscript to BioMed Central and take full advantage of:}

- Convenient online submission

- Thorough peer review

- No space constraints or color figure charges

- Immediate publication on acceptance

- Inclusion in PubMed, CAS, Scopus and Google Scholar

- Research which is freely available for redistribution 